\title{
La fotografía entre estudiantes de periodismo y comunicación audiovisual de las universidades públicas andaluzas: consumo, cultura visual y una propuesta pedagógica*
}

\begin{abstract}
Resumen
La irrupción de la tecnología smartphone en el campo de la fotografía ha provocado profundas convulsiones en el consumo, creación y difusión de las imágenes. Este sector, como ningún otro, ha tenido severas reformulaciones en la última década: la muerte de la fotografía réflex analógica a manos de la digital (DSLR), y la muerte de esta, a su vez, a mano de los smartphones, todo con el trasfondo de la sociedad red. Esa situación merece una profunda reflexión académica. Para nuestra investigación se ha diseñado una metodología basada en un total de 361 estudiantes de las asignaturas de fotografía de las facultades de comunicación de Andalucía (Universidad de Sevilla, Universidad de Cádiz, Universidad de Málaga y Universidad de Granada). Se ha escogido Andalucía por ser la comunidad autónoma con más habitantes de España, por lo que las facultades de Comunicación andaluzas tienen mucho peso en el panorama académico español y, además, posee lazos evidentes con Latinoamérica, lo cual es una de las señas de la universidad pública andaluza. Ello nos ha permitido, por un lado, tomar conciencia sobre cómo se relacionan estos estudiantes de comunicación con el medio fotográfico en la actualidad (luego de la implantación del Espacio Europeo de Educación Superior), pero, sobre todo, a partir de ese diagnóstico, nos ha permitido articular, en plena era Covid-19, una propuesta pedagógica de la enseñanza de la fotografía en el contexto educativo universitario que se ha implantado en el curso 2020/21 en la universidad pública de Cádiz, y cuya implantación se aprobó el curso anterior. Una nueva encuesta midió el grado de satisfacción por parte del alumnado.
\end{abstract}

Se ha tratado de una propuesta de praxis pensada para la alfabetidad visual del alumnado (capacidad de interpretar y crear imaginarios a partir del estudio del lenguaje visual). Este ejercicio de creatividad es competencia fundamental para la práctica del oficio de la comunicación.

\footnotetext{
* El presente trabajo se ha financiado como parte del proyecto de $\mathrm{I}+\mathrm{D}+\mathrm{i}$ Encrucijada de mundos: identidad, imagen y patrimonio de Andalucía en los tiempos modernos (P18RT-3026), del Programa del Ayudas a la I+D+i, en régimen de concurrencia competitiva, en el ámbito del Plan Andaluz de Investigación, Desarrollo e Innovación (PAIDI 2020), financiado por la Junta de Andalucía (España), cuyo Investigador Principal (IP) es el catedrático Juan José Iglesias Rodríguez, de la Universidad de Sevilla.
}

\author{
Manuel Blanco Pérez \\ Doctor en Filología y Comunicación. \\ Profesor, Universidad de Sevilla, \\ Sevilla, España. \\ Correo electrónico: \\ mblancoperez@us.es \\ ๑ orcid.org/0000-0003-1159-4679 \\ Google Scholar
}

Recibido: marzo 17 de 2021

Aprobado: junio 23 de 2021

Palabras clave:

alfabetidad visual, comunicación audiovisual, fotografía, pedagogía, periodismo. 


\section{Photography between Journalism and Audiovisual Communication students at Andalusian public universities: consumption, visual culture and a pedagogical proposal}

\begin{abstract}
The irruption of smartphone technology in the field of photography has caused profound disruption in the consumption, creation and dissemination of images. This sector, like no other, has undergone severe reformulations in the last decade: the death of SLR photography at the hands of digital (DSLR) photography, and the death of the latter, in turn, at the hands of smartphones, all with the background of the network society. This situation deserves a deep academic reflection. A methodology based on a total of 361 students of photography subjects of the Andalusian communication Faculties (Universidad de Sevilla, Universidad de Cádiz, Universidad de Málaga and Universidad de Granada) has been designed for this research. Andalucía has been chosen because it is the autonomous community with more inhabitants in Spain, which is why the Andalusian Communication Faculties have a lot of weight in the Spanish academic scene and, in addition, it has obvious links with Latin America, which is one of the hallmarks of the Andalusian public university. This has given the possibility, on the one hand, to become aware of how these communication students relate to the photographic medium today (after the implementation of the European Higher Education Area) but, above all, based on this diagnosis, it has allowed to articulate, in the middle of the COVID-19 era, a pedagogical proposal for the teaching of photography in the university educational context that has been implemented in the 2020/21 academic year at the public Universidad de Cadiz, and whose implementation was approved the previous academic year. A new survey measured the degree of student satisfaction. It has been a proposal of praxis designed for the visual literacy of students (ability to interpret and create imageries from the study of visual language). This exercise in creativity is a fundamental competence for the practice of the communication profession.
\end{abstract}

Key words:

visual literacy, audiovisual communication, photography, pedagogy, journalism. 


\section{Introducción y estado de la cuestión}

La fotografía, como vehículo artístico de expresión, pero también como herramienta para la documentación de la vida y el mundo, estuvo fundamentada en lo teórico a lo largo de todo el siglo XX en todos los aspectos posibles de su discurrir. Sin embargo, en apenas 15 años, los que van de 2005 a la actualidad, la fotografía, quizás como ningún otro arte y ninguna otra herramienta, mutó profundamente su ontología. En apenas 15 años se pasó de un sistema de profesionalización a otro de inmersión al microclima que supone la imagen digital en que, dicha formación, se da por sabida. Es decir, la fotografía desde sus orígenes hasta mediados de la década de los 2010, era estudiada como un oficio al que se llegaba desde múltiples formaciones de sustrato, que requería de gran destreza en su toma (hablamos de que todo fotógrafo profesional debía tener conocimientos de física, óptica, historia del arte...) que, a su vez, iba íntimamente ligada al revelado y positivado (química fotográfica): un proceso, el del laboratorio, imposible de abordar para un amateur o alguien sin formación en la materia. Aunque las cámaras compactas (en la última mitad del siglo XX) facilitaron la toma de fotografías por parte del ámbito doméstico (y, por tanto, turístico, etc.), estas no eran consideradas en ningún caso material profesional o artístico, sino un mero registro (familiar, vacacional) con valor de documento, pero carente de status de arte, y desprovista de toda intencionalidad autoral o científica (Martín Núñez et al., 2020).

La aparición y difusión a finales de esa década del 2010 de las Réflex Digitales (DSLR) supuso un primer shock en la industria: cámaras dotadas de un modo Auto y nuevos presets digitales que emulaban los conocimientos técnicos que se requerían hasta entonces en lo analógico, y que ofrecían un producto final ya "terminado". Tras eso, y en apenas un lustro, llegan a todos los países los smartphones cuya cámara es, hoy día, sensiblemente superior a cualquier cámara DRSL media de hace apenas 10 años; esto lleva la imagen fotográfica 
a otro status, pues ya desde la idea inicial esas imágenes nacen pensadas y diseñadas para el universo social media. Además, nunca hubo una tasa tan alta de cámaras fotográficas de gama alta (smartphone) en el mundo. Por tanto, el mecanismo comunicativo es radicalmente diferente en la fotografía actual que en cualquier etapa previa de esta.

El primer gran estudio sobre el grado de cultura fotográfica de los jóvenes lo hizo Pierre Bourdieu en Francia en los años 70 del siglo pasado. La fotografía, que había nacido en dicho país, goza de un status artístico y científico quizás no comparable a ningún otro país del mundo a día de hoy. El pueblo francés convive con la fotografía desde el nacimiento de esta (Soulage, 2005), motivo por el cual aún conservamos imágenes de la Francia de la década de 1840 (Sougez, 2011), si bien también hubo, en aquellos años, fotógrafos franceses (Jean Laurent, Joseph Jean Marie Lacoste) y británicos (Charles Clifford) que viajaron para documentar el mundo con el nuevo invento científico fotográfico (Newhall, 2002). Bourdieu, decíamos, vino a concluir que la convivencia de los franceses con la imagen era absoluta, y que incluso las cámaras compactas de aficionado servían para crear el hábito de consumo de imágenes de todo tipo, y entender la realidad que cohabita con las personas (Bourdieu, 2003).

Los trabajos sobre la ontología de la fotografía, y sus usos sociales, vinieron principalmente de los teóricos de la estética en torno a los años posteriores a la Revolución Industrial y antes de la Segunda Guerra Mundial, cuyos trabajos siguen siendo, hoy, reeditados y estudiados. Una fotografía teorizada en su concepción de nuevo arte para las masas, por autores como Walter Benjamin (2015) en los años 30 del siglo pasado. La fotografía pasa a ser, por derecho pleno, un arte, en los años 20 del siglo XX, y lo hará en la etapa de las vanguardias, gracias al desarrollo en su relación con las otras artes de las propias vanguardias (pintura, arquitectura, música, literatura...). Es, en este sentido, tangencial el trabajo visual de los artistas húngaros de esos años 20, 
que abrazan la fotografía desde múltiples artes previas de sustrato, y que a la postre tan importantes fueron en la historia universal de la fotografía, como el fotógrafo y profesor de la Bauhaus Làszló Moholy-Nagy (2004), György Kepes, o los fotógrafos Brassaï, Robert Capa o Kertész entre otros muchos. También de Centroeuropa era originario Man Ray (cuyos padres rusos emigran a EE. UU.), y que también cultiva un lenguaje artístico visual mestizo propio de las vanguardias. Beberá en especial de ramas tan alejadas de la fotografía como el trabajo del famoso sastre parisino y diseñador Paul Poiret:

El fotógrafo descubrió la gran colección de arte que poseía el diseñador y decidió usar muchas de las obras para sus fotografías, siendo consciente de que así les daba aplomo y un signo de distinción, como el pájaro de Brancusi, lo cual provocó que los diseños de Poiret y las fotografías en sí tuvieran una carga cultural evidente. (Fernández de Alarcón y González de la Rubia, 2020, p. 423)

Tras la postguerra mundial se retomará el viejo proyecto de la modernidad en la Europa de mediados del siglo XX, modificándose también la ontología fotográfica, en parte con trabajos tangenciales en los años 60 y 70 de Susan Sontag (2005), Roland Barthes (1980), Tagg (1988) o Dondis (2017) entre otros, que nos permiten calibrar el nivel de cambio que se produjo en una sociedad que cada vez más miraba al mundo de la imagen, y que se agudizará con la Ilegada, varias décadas después, de la esfera digital en la fotografía generalista (Marzal, 2007).

Hay antecedentes, desde las ciencias sociales y la dimensión pedagógica de la fotografía, en los trabajos de Chalfen (1987) y Spence y Holland (1991), que, siguiendo la línea que ya marcara Gisèle Freund (1974), lo vinculan a la antropología visual. Reseñable también es el trabajo de Martín Lister (2007) quien vincula los cambios en consumo de fotografía a los cambios en consumo del resto de bienes en la sociedad liberal que habita entre las crisis de las puntocom de 2000 y la crisis de 2008, y que podría decirse que tiene cierto carácter premonitorio (el uso/abuso de toda la iconografía entre los 
más jóvenes, vinculado al consumo desmedido de otros bienes, etc.). También existen estudios, más ensayísticos que metodológicos, del prolífico autor español Joan Fontcuberta (2008), quien ha reflexionado sobre la fotografía desde prácticamente todas las miradas posibles en su vínculo con la sociedad.

Los autores Nancy Van House y Morgan Ames (2007), de la Universidad de Berkeley (California), fueron de los primeros en estudiar el impacto de la nueva fotografía digital como vehículo comunicativo entre los jóvenes, y, por tanto, como mecanismo de representación identitaria, justo en un momento en que algunos terminales móviles (de muy alta gama) comenzaban a incluir rudimentarias cámaras fotográficas (en ocasiones de 0,2 megapíxeles).

En España, existe un trabajo de referencia sobre hábitos de consumo y usos de la fotografía digital entre jóvenes estudiantes de comunicación, desarrollado por los profesores Javier Marzal y María Soler Castellón (2011), y realizado en el momento en que la fotografía digital ya había desplazado a la fotografía analógica, pero previo, sin embargo, a la irrupción de los smartphones y previo, por tanto, a la era social media. En dicho trabajo, Marzal y Soler (2011) edifican su propuesta sobre el trabajo previo de otros autores, algunos de los cuales, ya en aquella época previa:

(...) hablan abiertamente de "la muerte de la fotografía" como consecuencia de la aparición de la fotografía digital que, de este modo, es entendida como un acontecimiento que habría transmutado la naturaleza misma del medio fotográfico, de tal manera que la fotografía se habría diluido en el universo de la imagen digital. (p. 110)

Es, así mismo destacable, un trabajo de innovación docente sobre fotografía vinculado a las TIC, circunscrito a la Universidad de Murcia (España): Morgado-Aguirre et al. (2015). En sentido opuesto, esto es: rescatando las técnicas más tradicionales y artesanales de la fotografía para su aplicación en el aula, se estructura el trabajo de Chaparro (2015), que profundiza en las 
posibilidades pedagógicas de la fotografía de revelado analógico (o numérica, en la formulación francesa), aunque aplicada al contexto actual:

Describir la práctica pedagógica a partir de la fotografía permite interpretar la experiencia de aula tanto en la fotografía como parte de los contenidos de Diseño Gráfico, primando la capacidad para reconocer las herramientas, técnicas y conceptos del lenguaje fotográfico y publicitario. (Chaparro, 2015, p. 167)

Y es que, en los últimos años, buena parte de las reformulaciones pedagógicas para con la fotografía han venido de Latinoamérica, en algunas de cuyas universidades públicas se han dado experiencias verdaderamente encomiables de alfabetidad audiovisual, recogidas en el trabajo de Pérez y Bedoya (2020) en que se teoriza desde el trabajo diario hasta los trabajos de Proyecto de Grado (o TFG, en la nomenclatura española). También hemos tenido oportunidad de estudiar, en fechas recientes, la fotografía en su vínculo con la historia como herramienta para descubrir el mundo pasado (Blanco Pérez y González Vilalta, 2020).

\section{Método (instrumentos)}

La asignatura de imagen fotográfica adquiere múltiples denominaciones en los diferentes programas universitarios públicos aprobados en las facultades de Comunicación de Andalucía en el marco del EEES (Espacio de Educación Europeo Superior, implantado a partir de 2010). En los grados de Comunicación Audiovisual y Publicidad (US, UCA, UMA y UGRA) suele adquirir la denominación de "Teoría de la Imagen", y, en los grados de Periodismo (US y UMA) las denominaciones de "Periodismo Audiovisual" o "Periodismo Tecnológico", siendo de carácter obligatoria en todos los grados de Comunicación Audiovisual y Publicidad, así como de Periodismo. Desde la creación de las viejas licenciaturas, ha sido tradicionalmente una asignatura (si bien con sus múltiples denominaciones) enfocada a la adquisición de 
contenidos básicos en la cultura visual tradicional y se planteó, incluso en el marco regulatorio del EEES, como una materia general de acceso a otras ramas de más profundidad epistemológica desde lo visual. Pero, como hemos dicho, esta materia ha cambiado tanto en la última década en lo tecnológico y en el uso que de ella hace la sociedad, que la relación del alumnado con las imágenes es radicalmente diferente a lo existente en la generación previa, cuando se crearon los programas. Por ello, se hacía indispensable conocer y medir la percepción del alumnado andaluz sobre esta asignatura, tangencial en el ámbito comunicativo, así como su conocimiento y cultura general sobre la propia fotografía.

Para ello, se diseñó una encuesta lo suficientemente abierta como para que pudiera responderla el alumnado de la asignatura "Teoría de la Imagen" del grado en Publicidad de la Universidad de Cádiz, del grado de Comunicación Audiovisual de las universidades de Sevilla y Málaga, y el alumnado de la asignatura "Fotografía y teoría de la imagen" del grado de Comunicación Audiovisual de la Universidad de Granada, en todos los casos asignatura obligatoria, así como de las asignaturas de "Periodismo gráfico" de la Universidad de Sevilla y la Universidad de Málaga.

Se ha escogido para la investigación Andalucía por ser, con mucho, la comunidad autónoma con más habitantes de España y una de las más grandes también de todo el ámbito europeo, además posee vínculos (de intercambio de profesores, alumnado y doctorados conjuntos) con Latinoamérica. La muestra que hemos podido completar responde a las siguientes facultades y cursos de universidades públicas andaluzas (Tabla 1): 
Blanco, M. / La fotografía entre estudiantes de Periodismo y Comunicación Audiovisual de las universidades públicas andaluzas: consumo, cultura visual y una propuesta pedagógica

Tabla 1. Universidades públicas andaluzas, facultades, grados, asignaturas y cursos

\begin{tabular}{|c|c|c|c|c|}
\hline Universidad & Facultad & Grado & Asignatura & Curso académico \\
\hline Sevilla & Comunicación & Publicidad y RR. PP. & Teoría de la imagen & Tercero \\
\hline Cádiz & $\begin{array}{l}\text { Ciencias Sociales y de la } \\
\text { Comunicación }\end{array}$ & Publicidad y RR. PP. & Teoría de la imagen & Primero \\
\hline Málaga & $\begin{array}{l}\text { Ciencias de la } \\
\text { Comunicación }\end{array}$ & $\begin{array}{l}\text { Comunicación } \\
\text { Audiovisual }\end{array}$ & $\begin{array}{l}\text { Teoría y análisis de la } \\
\text { imagen }\end{array}$ & Primero \\
\hline Granada & $\begin{array}{l}\text { Comunicación y } \\
\text { Documentación }\end{array}$ & $\begin{array}{l}\text { Comunicación } \\
\text { Audiovisual }\end{array}$ & $\begin{array}{l}\text { Fotografía y teoría de } \\
\text { la imagen }\end{array}$ & Segundo \\
\hline Sevilla & Comunicación & Periodismo & $\begin{array}{l}\text { Teoría y técnicas } \\
\text { audiovisuales } \\
\text { aplicadas al } \\
\text { periodismo }\end{array}$ & Segundo \\
\hline Málaga & $\begin{array}{l}\text { Ciencias de la } \\
\text { Comunicación }\end{array}$ & Periodismo & Tecnología de la CAV & Segundo \\
\hline
\end{tabular}

Fuente: elaboración propia.

La elaboración del cuestionario constó de 21 preguntas, con respuestas cerradas, basado en el tipo de encuestas científicas desarrolladas por los investigadores a los que aludimos antes, y que han sido actualizadas tratando de contextualizar la realidad social y formativa universitaria de hoy día. Las preguntas cerradas son más sencillas de codificar y preparar para su análisis y requieren un menor esfuerzo por parte de los encuestados, que no necesitan escribir o verbalizar pensamientos, sino únicamente seleccionar la alternativa que sintetice mejor su respuesta (Hernández et al., 2010).

En una primera fase de diseño de la investigación, las preguntas fueron enviadas a seis profesores de las diferentes universidades públicas andaluzas, investigadores todos del ámbito de la imagen y la fotografía, a fin de que validaran el cuestionario. Tras sus impresiones de vuelta, algunas de las preguntas fueron reformuladas y concretadas. Finalmente, se optó por una encuesta de tipo no experimental. Dentro de estas, y dado que se necesitaba 
interrelacionar varios ítems (o variables latentes) cribados y segmentados en su relación entre sí, optamos por un diseño de tipo transeccional y, dentro de este, correlacional/ causal. Tras tener las 21 preguntas, se formularon otras cinco cuestiones valorativas finales, de 1 (nada de acuerdo) a 5 (absolutamente de acuerdo).

La muestra final está constituida por 361 encuestas. Para realizar las entrevistas, se contó con la colaboración de los docentes que imparten las asignaturas aludidas en los centros universitarios públicos (tres docentes en la UMA, dos en la UGRA, dos en la US, y uno único en la UCA), que instaron a su alumnado a que rellenaran de forma individual y anónima el cuestionario digital. Como herramientas informáticas, se han empleado, por un lado, el software del paquete Google Docs en la nube (sistema de espacio virtual), seguido de un volcado a hoja de cálculo Excel para indexación de datos, y, posteriormente, para el cribado de cifras totales se ha usado el programa de tratamiento de datos estadísticos SPSS.

A partir de los datos recogidos, se han extraído las siguientes informaciones. Del total de encuestados (361), el 62,6\% (225) son mujeres, tres informantes, el $0,8 \%$ se declaran como género no binario y el $37 \%$ (133) son hombres. La edad mayoritaria es 18 años (33,5\%), seguida de 20 años (21,3\%), 21 años (14,2\%). En el otro extremo de la franja de edad, los mayores de 25 años (desde los 15 hasta los 41) apenas suman un 1\%. La distribución de estudiantes por universidades ha sido como sigue (Tabla 2): 
Tabla 2. Corpus de informantes por universidades

\begin{tabular}{ll}
\hline $\begin{array}{l}\text { Universidad pública } \\
\text { andaluza }\end{array}$ & $\begin{array}{l}\text { Alumnado matriculado en el curso 2020/2021 en la asignatura “Teoría de la imagen” (o sus } \\
\text { diferentes denominaciones según grado) que respondieron a la encuesta }\end{array}$ \\
\hline Sevilla & 102 \\
\hline Cádiz & 130 \\
\hline Málaga & 128 \\
\hline Granada & 24 \\
\hline
\end{tabular}

Fuente: elaboración propia.

Tras estas encuestas, que ofrecían una fotografía fidedigna del estado de la cuestión, y que mostraban varios de los déficits que se pretendían revertir, se desarrolló la propuesta de una nueva metodología de enseñanza de las asignaturas de imagen digital (recogida en un proyecto de innovación docente y aprobado por el rectorado de la Universidad de Cádiz) que recogiera una nueva apuesta por hacer pivotar los contenidos en torno a un trabajo creativo visual personal de cada alumno (se explicará al detalle en el apartado "Propuesta de desarrollo del Proyecto Fotográfico personal"). Esa nueva propuesta se implantó en el curso 2020/2021 y, al término de la asignatura cuatrimestral (en febrero de 2021), se volvió a pedir al alumnado que la cursó que respondiera a una nueva encuesta. La encuesta se diseñó con 21 preguntas sobre cómo se desarrolló el trabajo personal, sobre la adquisición de los contenidos y sobre la asimilación de bibliografía y trabajo de autores.

Tratamos, por tanto, de preguntarnos qué tipo de consecuencias ha tenido la irrupción de los social media (algunos de ellos pensados por y para el universo fotográfico digital, como la app Instagram entre otras) en los jóvenes estudiantes de comunicación de Andalucía. Una comunidad donde los estudios de comunicación llevan implantados más de 30 años, y donde nunca se ha hecho una investigación sistemática sobre la base de la cultura fotográfica y 
su funcionamiento entre el alumnado de las cuatro universidades públicas que ofrecen sus grados en Comunicación Audiovisual y Periodismo.

\section{Análisis}

En primer lugar, se formularon las preguntas sobre la realización de fotografías por los estudiantes de comunicación y periodismo. Se constata un desplome en el uso de la réflex digital (figura 1), que ha sido prácticamente sustituida, en el día a día, por los smartphones: un 55,9\% de los informantes afirma usar el smartphone a diario, mientras que, en la réflex, ese uso diario apenas representa un $2,4 \%$.

¿Con qué frecuencia haces fotos con tu Réflex Digital?
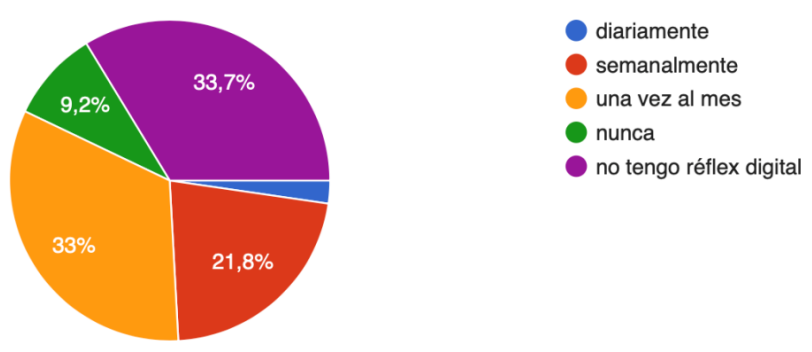

Figura 1. Frecuencia de uso réflex digital. Fuente: elaboración propia.

De hecho, a la pregunta de cuánto se usó semanalmente la réflex, la respuesta más mayoritaria, con un 33,7\% de los encuestados, es "no tengo cámara réflex digital", seguida de la respuesta de uso "una vez o menos al mes" (33\%). 
Además, un 9,2\% afirma no haber disparado jamás en una cámara réflex, y un $29,8 \%$ de los encuestados jamás ha visto un rollo de película fotográfica (foto química), sumado a un 10,6\% que afirma no estar seguro de qué es (figura 2).

\section{¿Con qué frecuencia haces fotos con tu smartphone?}

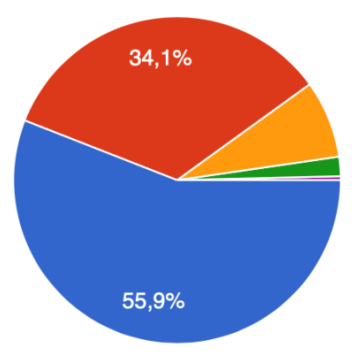

diariamente

semanalmente

una vez al mes

nunca

no tengo smartphone

Es, a nuestro juicio, alarmante, que el alumnado que no tiene cámara réflex, sumado a los que jamás han disparado en una cámara réflex, represente un $43,5 \%$ del total de estudiantes de comunicación y periodismo en el año 2021. Ello supone, creemos, una laguna formativa de primer orden de cara a la empleabilidad laboral de postgrado y a la especialización posterior en imagen digital (tanto para periodistas como para comunicólogos).

Con respecto a los hábitos de consumo de fotografías, el cuestionario incluía varias preguntas sobre este particular. El estudio revela que el 38,4\% de los estudiantes de la muestra analizada nunca ha visitado una exposición fotográfica. El 58\% de los informantes afirma visitar entre dos o tres exposiciones al año. 
Frente a ello, apenas un 3,5\% afirma ir a alguna exposición mensualmente. Con respecto al consumo de libros de fotografía (tanto de teoría como de monografías de autores o miscelánea), el 82,7\% de los informantes afirma no haber comprado, jamás, un libro de fotografía, seguido de un 14,1\% que afirma comprar uno al año, y un 2,4\% de informantes que afirma adquirir "tres o más al año". Cuando se les pregunta a los informantes si conocen alguna editorial de libros de fotografía, se producen 255 respuestas, pero de ellas solo 7 son editoriales reales (Fábrica, Taschen, Anaya, Lunwerg, GG, Blume, Thames \& Hudson), 245 responden con frases de negación del tipo "no te sé decir", "ni idea", "no consumo libros", "la vdd q no", "Ahora mismo ni idea jajaja" o "no :(", entre otros. Finalmente, tres informantes nombran a la empresa de libros autopublicados digitales en papel Hoffman.

Sin embargo, aunque la asistencia a salas de exposiciones o museos para el consumo de la fotografía sea tan baja, y la compra de libros/catálogos sea muy minoritaria, a la pregunta de ¿sigues a algún fotógrafo en Instagram?, la respuesta es afirmativa para un $65,2 \%$ de los informantes. Un 10,7\% afirma que "tal vez" sigue a dichos fotógrafos o influencers, frente a un 24,1\% que afirma no seguirlos. Es decir, que las fuentes de culturización de la imagen fotográfica han mutado de forma radical en los últimos años, pasando del museo y la moqueta de la sala a las pantallas del smartphone.

Con respecto a los géneros fotográficos de interés mayoritario, destaca un $73,7 \%$ de informantes que afirma decantarse por "paisaje o naturaleza". Seguido de un $71 \%$ que afirma cultivar la fotografía callejera (o Street Photo). Un 61,2\% afirma tener predilección por el retrato. El 54,5\% afirma decantarse por "cosas cotidianas, pero desde otro punto de vista", seguido de la fotografía de desnudo o erótica. Esta diferencia de resultados no guarda relación alguna con la procedencia de la carrera de los estudiantes, puesto que un cribado por titulaciones arroja unos datos prácticamente iguales. 
Se les preguntó a los informantes qué es lo que más valoran en una fotografía: el $89,4 \%$ respondió que la "originalidad", seguido de los que afirman que "la composición" (69\%) y, en tercer lugar, "su perfección técnica" (25,9\%). En cuarto lugar, están los informantes que afirman valorar "que me recuerde al trabajo de otros autores" (6,3\%). Tras ellos, se sitúan los que afirman que lo que más valoran es "que la haya hecho un amigo de Instagram" $(5,1 \%)$.

Cuando se pregunta por el sempiterno debate fotográfico sobre imágenes a color o en blanco y negro, el 78,6\% vincula la respuesta a que la fotografía sea de un tema u otro, un 19,1\% elige "color, siempre", y un 2,3\% que elige "blanco y negro, siempre".

En lo que respecta a conocimientos específicos sobre cultura fotográfica, cuando se les pidió que citaran a fotógrafos cuya obra les interesaba especialmente, las respuestas revelaron una falta alarmante de referentes claros entre los informantes. Del total de respuestas (141), casi la mitad (44\%) son: "no recuerdo", "ninguno", "no sé" y derivados. De los que sí aciertan correctamente, destacan los siguientes nombres: Chema Madoz (11), Sebastián Salgado (9), Robert Capa (10), David Lachapelle (2), Robert Frank (1), Henri Cartier-Bresson (10), etc. Las mujeres fotógrafas apenas son nombradas, solo tres: Annie Leibovitz (7), Eve Harnold (1) y García Rodero (1). Varios nombres responden a avatares de Instagram, y no siempre fotógrafos profesionales: @devonart_(1), @paoloraeli (1), @greyheavens (1), @ hiclavero (1).

Sin duda, la cultura fotográfica es, actualmente, adquirida a través del consumo de los social media. A la respuesta de "qué redes sociales posees", el 96,1\% posee Instagram, seguido de un $82,9 \%$ que posee Twitter. Muy lejos de ello, con un $49,8 \%$ aparece la china TikTok, que ya ha desbancado a Facebook (35\%). Muy lejos aparecen Pinterest $(3,1 \%)$, y prácticamente irrelevante es la otrora poderosa Flickr $(0,8 \%)$. 
Además de por las redes sociales, asistimos en la actualidad a la nueva ventana de consumo de contenidos audiovisuales que suponen las novedosas plataformas: Netflix, Filmin, HBO, Amazon Prime, Movistar+, Disney+, etc., que, pese a llevar implantadas menos de cinco años, ya han dado lugar a una serie de cambios estructurales en el consumo del audiovisual, "generando un nuevo marco de consumo audiovisual” (Blanco Pérez, 2021, p. 22).

Por último, la parte final de la encuesta se diseñó para explorar los vínculos de estas asignaturas y, en general, de estas titulaciones, con el mercado laboral; los informantes parecen haber asumido dicha necesidad. A la pregunta valorativa de "tener conocimientos en imagen es útil para dedicarse profesionalmente al mundo de la comunicación", el 70,4\% de los informantes adjudicaron valor máximo (5) a la aseveración. Otro 19,5\% adjudicó valor 4. Un 7\% valor 3 (medio). Apenas un 2,3\% adjudicó valor 2 y solo un 0,8\% valor 1 . Se preguntó, además, si el smartphone había democratizado el acceso a lo fotográfico, donde un 66,5\% respondió con el valor máximo a la aseveración (5), un 28\% le adjudicó un valor 4 , y apenas un 4,7\% adjudicó valor 3. Cayendo hasta el $0,4 \%$ los valores 2 y 1 .

Asimismo, se quiso conocer de primera mano qué piensan los informantes sobre la censura en Instagram. Solo un $0,4 \%$ considera que la censura es muy buena (5), un 3,5\% le adjudica 4 (buena), un 14,8\% le adjudica valor 3 (regular), y la mayoría de los informantes cree que la censura es nociva: el valor dominante es el 53,3\% valor 1, seguido de un 28\% para el valor 2 . Por último, se quiso conocer si los informantes consideran que los contenidos de las asignaturas de fotografía son útiles para su formación: los informantes que consideran que son nada útiles $(2,7 \%$, valor 1$)$ y poco útiles $(9,3 \%$, valor $2)$, son claramente una minoría. Una aplastante mayoría considera que los contenidos en fotografía son muy útiles $(28,4 \%$, valor 4$)$, seguidos de medio útiles $(28,4 \%$, valor 3$)$ y de totalmente útiles $(20,2 \%$, valor 5$)$. 


\section{Resultados y discusión}

Como ya se ha dicho, casi la mitad de los estudiantes de comunicación y periodismo andaluces no usan nunca una cámara de fotos. Además, y aunque no deja de ser preocupante que un $38,4 \%$ de los estudiantes andaluces de comunicación y periodismo nunca visite exposiciones de fotografía, es cierto que se demuestra la tendencia a un cambio de la fuente de consumo de imágenes y material fotográfico, pues el $65,2 \%$ del alumnado sigue el trabajo de fotógrafos profesionales a través de las redes sociales de estos.

En este sentido, creemos que la inconsistencia en las respuestas de si podían identificar alguno de los grandes fotógrafos de la historia, tiene que ver con la cada vez más escasa cultura general, cosa que ya viene constatándose curso a curso desde hace años. Pero, también es justo decir, que la lógica de las universidades públicas andaluzas no es que favorezca precisamente la docencia y la enseñanza de calidad: en los meses que duró la encuesta, varios de los profesores de las asignaturas estudiadas perdieron sus trabajos por ajustes de créditos departamentales (tanto en la Universidad de Sevilla como en la de Cádiz), habiendo recaído la docencia, tradicionalmente, en profesores sustitutos a tiempo parcial sin ningún tipo de estabilidad laboral ni formación fotográfica específica.

\section{Límites de la investigación realizada}

La investigación realizada posee ciertas limitaciones. En primer lugar, que la docencia ha presentado la anomalía propia de las medidas contra la Covid-19 que, en el caso andaluz, ha significado disponer de solo un mes presencial (octubre de 2020), pasándose todos los demás meses a la docencia virtual. 
En segundo lugar, al no ser homogéneos los planes de estudio de las universidades públicas andaluzas, nos encontramos con unas materias que no siempre están ubicadas en el mismo curso, y que, además, son muy estáticas en su bibliografía y herramientas conceptuales (o lo son, al menos sobre el papel, con unos planes de estudios planteados previos a la irrupción de los smartphones, e incluso de los social media).

Sería deseable, en un segundo paso, hacer extensivo este trabajo a otras áreas geográficas, a fin de comparar las particularidades de la docencia en relación a cada perfil de alumnado en función del centro en que estudie.

Por último, pensamos que sería deseable una mayor decisión en los órganos de gobierno a la hora de prestigiar la innovación en la docencia en las universidades públicas andaluzas, un impulso real para la consolidación de plantilla de docentes acreditados, y una menor burocratización.

\section{Propuesta de desarrollo del proyecto fotográfico personal}

Con estos datos, a modo de diagnóstico, era necesario articular una propuesta pedagógica para una alfabetidad visual de los estudiantes andaluces de las facultades de comunicación y periodismo.

Los estudiantes comprenden qué es la imagen (precisamente en un contexto sobresaturado de ellas), reflexionan críticamente y articulan una historia narrativa visual en torno a un tema, que será trabajado por ellos, individualmente, desde un horizonte de expectativas que incluye otras obras del cine, novela, poesía, diseño o recorrido por escuelas visuales diversas. 
Para abordar el aprendizaje de la teoría de la imagen y el ejercicio de la alfabetidad visual de nuestra propuesta metodológica, partimos inicialmente de ejercicios de lectura, vídeos de autores y reflexión actualizada en torno a los tópicos latinos: Ubi Sunt, Carpe Diem, Locus Amoenus, Beatus Ille, Memento Mori, Recusatio, etc.

Se recomendó realizar los trabajos con una cámara de fotos DSLR, pero por el contexto Covid-19 y por la aparición de apps de smatphone que imitan el modo manual de las DSLR, se les permitió también usar celular para los trabajos.

\section{Introducción y presupuestos técnicos}

Nuestra propuesta docente, en primer lugar, consistió en conseguir hacer reflexionar en ciertos temas filosóficos al alumnado, a través de los tópicos latinos, e iniciamos una fase de articulación conceptual visual, con el ejemplo de actividades propuestas, en su día, por John L. Debes, Clarence Villiams, Colin Murray y Turbayne, autores americanos de los años 50 que, de la mano de la entonces todopoderosa Kodak, lanzaron una campaña en la Escuela de Rochester (EE. UU.) para la alfabetidad visual. El experimento, en especial la obra de Debes, aparece citado y actualizado en un reciente estudio de López-León (2017). Si bien, en nuestro caso, hemos pretendido aplicar ciertos coeficientes correctores, propiciados por el cambio de modelo derivado de la no presencialidad provocada por la pandemia de la Covid-19 en la fecha actual. 


\section{Desarrollo del temario}

Si bien la propuesta pedagógica ha resultado ser una herramienta en constante evolución, y con una filosofía "de beta constante" (en estado de permanente reformulación), sí pueden extraerse ya varias propuestas en firme. Quisimos dar importancia a la parte de trabajo práctico (praxis) frente a la teorización de conceptos, desgajando para los estudiantes los contenidos en torno a los tres ejes siguientes:

1. Literatura y Fotografía.

2. Pintura, Diseño y Fotografía.

3. Periodismo, Reporterismo y Fotografía.

\section{Metodología}

Lo metodológico, en su aplicación didáctica, se desarrolló en las actividades teóricas (2h/semana) y prácticas (2h/semana) de clase. Estuvieron fijadas en dos horas por semana para cada uno de los grupos de 50 alumnos. Cada uno escogía un tema y comenzaba a trabajarlo siguiendo ciertas pautas metodológicas. Las clases prácticas pivotaron en torno a sesiones de visionado crítico y resolución de problemas técnicos o conceptuales de ese material gráfico que, semana a semana, traía el alumnado. Se trató de vincular, por tanto, las herramientas aprendidas en la teoría con el desarrollo de la práctica.

Por tanto, cada visionado constaba, por regla general, de tres partes: 
1. Conceptualización de la imagen (lectura de documentos, escritura de conceptos y discusión en clase sobre visionado de otros autores o material de los compañeros).

2. Reflexión sobre los errores formales y conceptuales del material gráfico del alumnado.

3. Elaboración de una propuesta de mejora del material basado en las imágenes entregadas al profesor para la corrección.

Se les propuso, de forma voluntaria, y en pleno contexto en que la imagen es digital y volátil, elaborar físicamente un álbum con las imágenes impresas junto a textos redactados por el propio alumnado, para que usaran la narración, no como explicación de la pieza gráfica, sino integrada como diálogo con lo visual. Esta propuesta estuvo inspirada en la cultura maker que busca generar, en el alumnado, la curiosidad por la creación de artefactos físicos, palpables, con sus propias manos, y que está recibiendo un número ingente de atención desde la pedagogía actual (Vuopala et al., 2020).

Dado el carácter piloto de este proyecto de innovación docente, se decidió pedir al alumnado, una vez acabada y evaluada la asignatura, que respondieran a una encuesta anónima donde se les preguntaba por las particularidades de la metodología y la dinámica de trabajo. Se basó en unos datos previos de control estadístico y unas consideraciones generales sobre el temario: la adquisición de competencias, habilidades y destrezas adquiridas en virtud de lo experimentado en el aula y fuera de ella para la elaboración del proyecto fotográfico. 


\section{Temas de aplicación teórica}

Los temas fueron elegidos libremente por el alumnado, si bien el docente les instó a pensar en varios ítems de arranque. Se han trabajado los siguientes aspectos:

- Diálogo entre fotografía: se pidió al alumnado que buscara fotografías antiguas de su familia

- Retrato y metafotografía: se pidió que retrataran a familiares mayores (abuela, abuelo) integrando, en el propio retrato, la vieja fotografía de los abuelos con la imagen actual de los jóvenes, propiciando así una reflexión visual intra-fotográfica y transgeneracional.

- Diálogo intergeneracional: se pidió que mantuvieran una charla sobre el contexto de esa vieja foto de juventud: tratar de conocer el país de la época, las costumbres de entonces, etc., desde la oralidad conversacional.

- Horizonte de expectativas: el docente trató de encauzar la creatividad del alumnado vinculando los temas elegidos, y el material obtenido por cada uno, a otros lenguajes artísticos: películas, novelas, obras literarias, y, por supuesto, autores fotográficos, diseñadores, arquitectos, etc.

Tras esa fase inicial, el alumnado tuvo un mes de margen para elegir un tema concreto de proyecto. Solo 4 de 124 cambiaron la temática en el desarrollo del proyecto, y de ellos, dos, lo hicieron obligados por las restricciones de movimiento impuestas por la pandemia de la Covid-19 en España en el otoño de 2020. Los temas más trabajados por el alumnado, quedarían, por tanto, como siguen en la Tabla 3. 
Blanco, M. / La fotografía entre estudiantes de Periodismo y Comunicación Audiovisual de las universidades públicas andaluzas: consumo, cultura visual y una propuesta pedagógica

Tabla 3. Temas, subtemas, alumnos por cada propuesta y géneros fotográficos

\begin{tabular}{|c|c|c|c|}
\hline Tema & Subtema & $\begin{array}{l}\text { Número } \\
\text { alumnos } \\
\text { que lo } \\
\text { trabajaron }\end{array}$ & Vinculación con géneros fotográficos \\
\hline Familia & Mi abuela & 27 & Reportaje color, BN, fotoperiodístico \\
\hline Autorretrato & Selfie en ambiente & 27 & $\begin{array}{l}\text { Localización: hogar (ninguno en } \\
\text { exteriores) }\end{array}$ \\
\hline Metafotografía & Ciudad & 15 & Street photo \\
\hline Familia & Abuelo & 14 & Fotografía humanista \\
\hline Mascotas & Perro / gato & 12 & Reportaje actualidad en su entorno \\
\hline Identidades sexuales & Retratos contra homofobia / queer / otros & 11 & Vanguardias. Retrato clásico. \\
\hline Paisaje & Naturaleza & 5 & Fotografía clásica F64 \\
\hline Ansiedad & Retratos & 5 & Vanguardias. Retrato clásico. \\
\hline Soledad & Retratos & 5 & Vanguardias. Retrato clásico. \\
\hline Amigos & Retratos grupo & 4 & Reportaje clásico \\
\hline
\end{tabular}

Fuente: elaboración propia

\section{Entrega de trabajos prácticos y resultados}

La entrega del proyecto fotográfico personal estuvo programada para ser subida a la plataforma digital de la universidad en una fecha acordada. Consistió en una presentación en PDF (120) o PowerPoint (4). En el caso de los PowerPoint, los cuatro incluían música (efecto extradiegético). Todo el alumnado entregó la práctica final en fecha. 


\section{Consideraciones por parte del alumnado}

Como se ha dicho anteriormente, una encuesta específica entre el alumnado de la Universidad de Cádiz de lo que ha supuesto para ellos el proyecto presente, se realizó después de la entrega final. La encuesta fue voluntariamente respondida por 109 de los 124 matriculados. De ellos el $76,1 \%$ (83) son mujeres, el $22,9 \%$ (25) hombres y el 0,9 (1) se declara como no binario. La franja de edad mayoritaria es de 18 años, con un 66,1\% del total; los mayores de 24 años apenas representan un 0,9\% del total.

Se pidió a los informantes que valoraran el proyecto de innovación docente, en términos generales, de 5 (perfecto) a 1 (pésimo): el $67,9 \%$ le otorgaron 5 (74 informantes), el 27,5\% le otorgaron un 4 (30 informantes), en la línea media de la calificación (3, mediocre) se encontraron 5 votos, el 4,6\% del total. No hubo ni un solo voto para 2 (muy malo) o 1 (pésimo). (Figura 3).
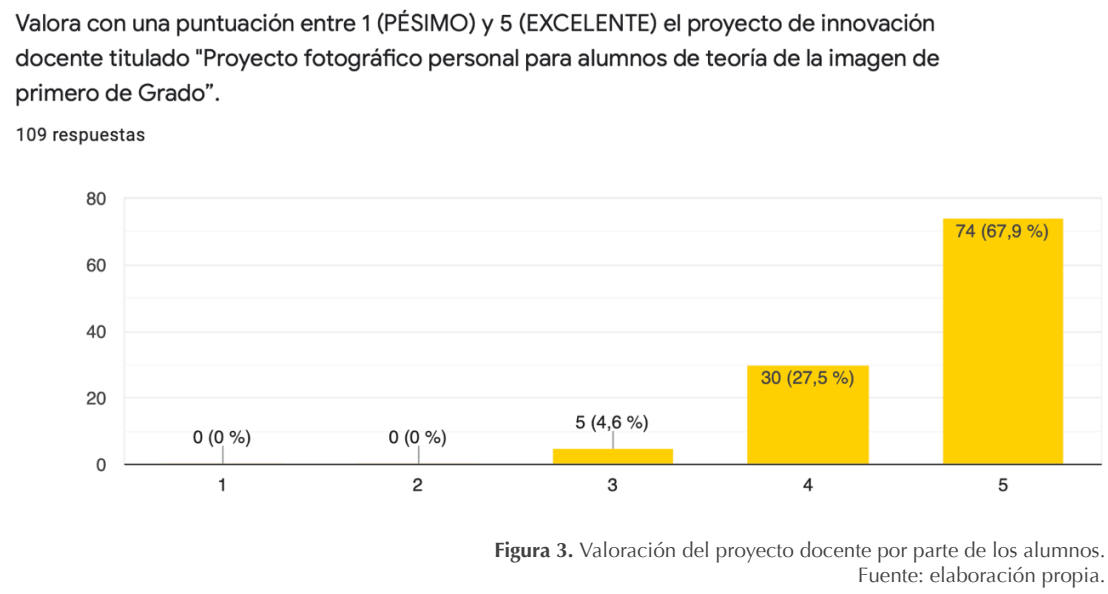
Preguntados sobre si era, a juicio de los informantes, una buena forma de conectar los contenidos de la asignatura con el futuro desempeño de profesional de la comunicación, y estando, también, establecidas las respuestas de 5 (perfecto) a 1 (pésimo): el 75,2\% le otorgaron 5 (82 informantes), el 21,1\% le otorgaron un 4 (23 informantes), en la línea media de la calificación (3, mediocre) se encontraron 2 votos, el 1,8\% del total, y un solo voto para 2 y ningún voto para la opción 1 (Figura 4).
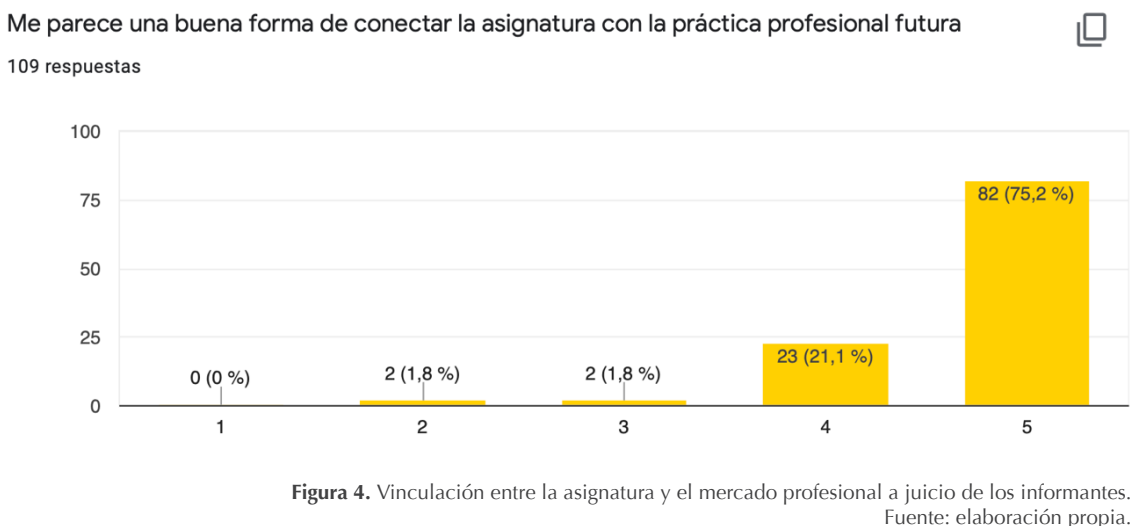

A la pregunta de si ha sido útil para el aprendizaje en materia de imagen, las respuestas quedan como siguen, siendo siempre establecidas las respuestas de 5 (perfecto) a 1 (pésimo): el 64,2\% le otorgaron 5 (70 informantes), el $22,9 \%$ le otorgaron un 4 (25 informantes), en la línea media de la calificación (3, mediocre) se encontraron 12 votos, el $11 \%$ del total, y solo dos votos para 2 (muy malo). Ningún voto para la opción 1 (pésimo). En línea con esta pregunta anterior, se preguntaba también por la pertinencia de esta actividad de cara al diseño de un portfolio personal (cv creativo), siendo estos los datos, y como siempre establecidas las respuestas de 5 (perfecto) a 1 (pésimo): el 64,1\% le otorgaron 5 (71 informantes), el 23,9\% le otorgaron un 4 (26 informantes), en la línea media de la calificación (3, mediocre) se 
encontraron 9 votos, el 8,3\% del total, y solo dos votos para 2 (muy malo) y otro voto para la opción 1 (pésimo).

Por último, se preguntó a los informantes si esta actividad les ha parecido una buena forma de conectar su formación con el trabajo de alguno de los fotógrafos más importantes de la historia. Los datos son los que siguen, una vez más establecidas las respuestas de 5 (perfecto) a 1 (pésimo): el 78\% le otorgaron 5 (85 informantes), el 20,2\% le otorgaron un 4 (22 informantes), en la línea media de la calificación (3, mediocre) no se encontró ningún voto, solo dos votos para 2 (muy malo) y, de nuevo, ningún voto para la opción 1 (pésimo). (Figura 5).
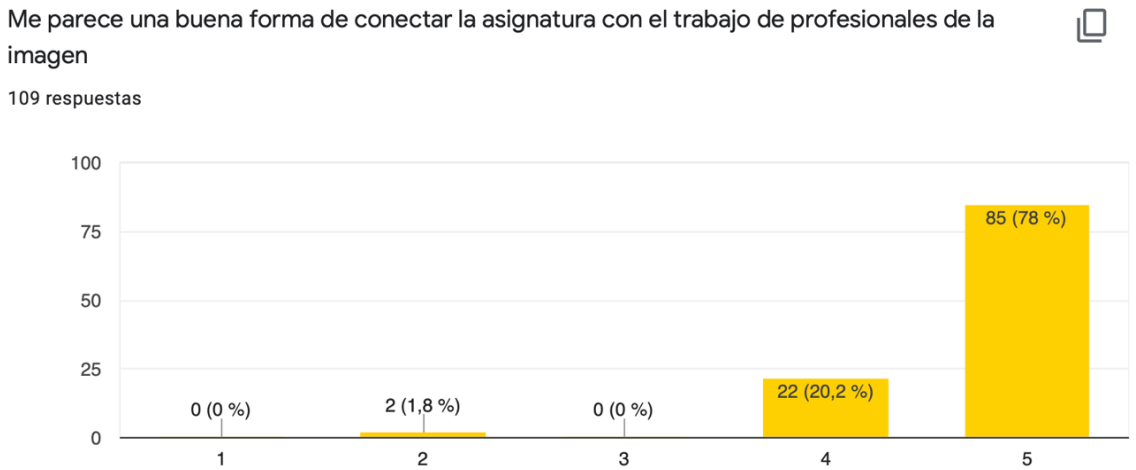

Figura 5. Vínculo entre asignatura y fotógrafos profesionales a juicio de los informante. Fuente: elaboración propia.

Con respecto a otros datos de interés preguntados, el 80,7\% de los informantes manifestó que ha leído algún libro, visto alguna película o profundizado en algún autor a raíz de lo visto en clase. Por último, y con respecto al perfil del 
profesor, siendo la comunicación una rama fuertemente profesionalizada, en tanto oficio que es, se les preguntó si creen que el hecho de que el docente sea profesional del sector, además de académico, influye o no en la impartición de la asignatura. El 57,8\% (63 encuestados) le da el valor máximo a tal hecho, seguido de un 28,4\% (31 informantes) que le da 4 de 5 en la escala de importancia. Apenas un $11 \%$ cree que la importancia de ello es moderada o intermedia (12 informantes), frente a un informante que da valor 2 (muy poca importancia) y dos con valor 1 (ninguna importancia).

\section{Conclusiones}

A modo de síntesis final, podemos convenir que los actuales estudiantes de Comunicación Audiovisual / Publicidad y Periodismo de las universidades públicas andaluzas, han sustituido mayoritariamente la fotografía digital réflex (DSLR) por los smartphones, que, a su vez, disparan de forma compulsiva para compartir en redes (principalmente Instagram), y que, en cambio, poseen una baja/muy baja cultura visual fotográfica. Más de la mitad nunca ha disparado una fotografía en una cámara fotográfica. Es manifiesto que el diseño de los planes de estudio previos a la implantación de los smartphones les genera poca motivación por estudiar o profundizar en el campo de la fotografía, pese a ser conscientes de la importancia del estudio de la imagen para su futura inmersión profesional.

Se constata que, en la falta de cultura visual de nuestros estudiantes de comunicación andaluces, intervienen muchos elementos, y excede los motivos de este estudio el indagar en las causas: nos hemos centrado en las consecuencias y en proponer, implantar y medir un sistema alternativo de alfabetidad visual. 
Es necesario repetir, las veces que haga falta, que la comunicación no es, y no puede ser nunca, solo una enseñanza técnica y teórica, es un oficio. Y como tal, requiere de una planificación que no esté de espaldas al desarrollo profesional real. Los docentes, para una buena enseñanza de este oficio (comunicativo y periodístico), deben conocer el sector profesional. No basta con una mera adquisición de contenidos teóricos, desde la comodidad de la biblioteca de la Facultad, sino desde la praxis laboral, pues solo así podrán guiar a los estudiantes: de forma parecida a como un maestro guía a un aprendiz en cualquier oficio tradicional. Ello es conceptualmente impensable en la lógica universitaria actual andaluza, que ha invertido ingentes cantidades de presupuesto en material técnico para las TIC (Rodrigo et al., 2017), pero poco en profesores que lo sepan saber usar técnicamente, pues rara vez han tenido trayectoria profesional más allá de las aulas.

Es, asimismo reseñable, el mal uso de las figuras de profesor asociado y profesor sustituto interino que se han dado por parte de los departamentos universitarios andaluces, pues en Andalucía han servido mayoritariamente no para la participación puntual en alguna materia universitaria de un reconocido profesional, sino para cargar el peso estructural del grueso de créditos de asignaturas que, las figuras más consolidadas de los departamentos, no han sabido o querido impartir. El sistema universitario andaluz sigue con modelos pedagógicos pensados antes de la irrupción de las multipantallas actuales. La precarización, sistémica en el caso andaluz, a la que aludíamos, de los docentes que han de desempeñar esta función no es, obviamente, un elemento que ayude a su innovación desde dentro, y a la consolidación de proyectos y nuevas pedagogías de la imagen.

Con todo, y a tenor de los datos ofrecidos, podemos constatar que una reformulación de los contenidos de las asignaturas de Imagen, en las diferentes asignaturas de las facultades de comunicación andaluzas, en la línea en que 
aquí se ha expuesto, redundaría en un mejor conocimiento del oficio y de la obra de los fotógrafos de referencia en este medio. También, significaría aplicar los conceptos teóricos a la creación de contenidos propios por parte del alumnado, redundando en un mayor potencial creativo y expresivo, a través de la imagen, y en una mejor integración, en definitiva, de la mayoría de elementos que componen la cultura de la imagen en el oficio de un profesional de la comunicación.

Quizás la voluntad política andaluza no vaya en la misma dirección que la que propone este trabajo. Pero los datos demuestran que reformular y actualizar lo antiguo, poniendo la creación personal del alumnado en el centro, significa un mayor conocimiento, y reconocimiento del mundo que tenemos. No se nos antoja mala premisa, de entrada, para apostar por la enseñanza pública andaluza como motor de transformación y cambio social futuro y hacerlo, también, a través de la imagen.

\section{Referencias}

Barthes, R. (1980). La cámara lúcida. Planeta.

Benjamin, W. (1931) [2015]. Breve historia de la fotografía. Casimiro. (Original publicado en 1931).

Blanco Pérez, M. (2021). Cine y Semiótica Transdiscursiva. Comunicación y Sociedad, 19, 1-22.

Blanco Pérez, M. y González Vilalta, A. (2020). La Barcelona de la Guerra Civil española a través de la mirada de Antoni Campañà. Análisis fotográfico e histórico. Historia y Comunicación Social, 25(2). 309-321. http://dx.doi.org/10.5209/hics.69993

Blanco Pérez, M. (2021). Cine y Semiótica Transdiscursiva. Comunicación y Sociedad. Año 19. $1-22$.

Bourdieu, P. (2003). Un arte medio. GG. 
Chalfen, R. (1987). Snapshot Versions of Life. Bowling Green. Bowling Green State University Popular Press.

Chaparro, S. Y. (2015). Una mirada en blanco y negro: resignificación de la fotografía. Kepes, 11, 163-175. 10.17151/kepes.2015.12.11.9

Dondis, D. A. (1973) [2017]. La sintaxis de la imagen. GG.

Fernández de Alarcón, B. y González de la Rubia, M. I. (2020). Leer entre costuras: la conexión entre la estética y la sociedad en el siglo XX. Bajo Palabra, 24, 415-430. https://doi. org/10.15366/bp.2020.24.021

Fontcuberta, J. (2008). Historias de la fotografía española. Escritos 1977-2004. GG.

Freund, G. (1974) [2017]. La fotografía como documento social. GG.

Hernández, R., Fernández, C. y Baptista, P. (2010). Metodología de la investigación. McGrawHill.

Lister, M. (2007). A Sack in the Sand. Photography in the Age of Information. Convergence: The International Journal of Research into New Media Technologies, 13(3). 251-274. https://doi. org/10.1177/1354856507079176

López-León, R. (2017). El aula de diseño como escenario de exploración entre alfabetidad visual y pensamiento crítico. Kepes, 15, 173-194. 10.17151/kepes.2017.14.15.7

Martín, M., García, S. y Rodríguez, A. (2020). Conservar, conversar y contestar. Grietas y relecturas del álbum familiar. Arte, Individuo y Sociedad, 32(4), 1065-1083. https:// dx.doi.org/10.5209/aris.66761

Marzal, J. (2007). Cómo se lee la fotografía. Cátedra.

Marzal, J. y Soler, M. (2011). Hábitos de consumo y usos de la fotografía en la era digital entre estudiantes de comunicación. Comunicar, XIX(37), 109-116. http://dx.doi.org/10.3916/ C37-2011-03-02

Moholy-Nagy, L. (1925) [2004]. Pintura, Fotografía, Cine. GG.

Morgado-Aguirre, B., López-Martín, E. y Conesa-Tejada, S. (2015). El uso de las TIC en la enseñanza universitaria de la fotografía. Primeros resultados del proyecto de innovación docente de la Universidad de Murcia. Arte, Individuo y Sociedad, 27(2), 295-319. http:// dx.doi.org/10.5209/rev_ARIS.2015.v27.n2.45150

Newhall, B. (2002). Historia de la fotografía. GG. 
Pérez, J. A. y Bedoya, C. M. (2020). La fotografía como herramienta para el desarrollo de la creatividad y la alfabetidad visual: investigación en el aula. Kepes, 16(20), 377-404. 10.17151/kepes.2019.16.20.14

Rodrigo, D., Aguaded, I. e Iglesias, M. (2017). La universidad andaluza ante las TIC. En Aguaded (Ed.), La educación mediática en entornos digitales. Retos y oportunidades de aprendizaje (pp. 51-72). Egregius.

Sontag, S. (1997) [2005]. Sobre la Fotografía. Alfaguara.

Sougez, M.-L. (2011). Historia de la fotografía. Cátedra.

Soulage, F. (2005). Estética de la fotografía. La Marca.

Spence, J., \& Holland, P. (1991). Family Snaps: the Meaning of Domestic Photography. Virago.

Tagg, J. (1988). The Burden of representation: Essays on Photographies and Histories. University of Minnesota Press.

Van House, N., \& Ames, M. (2007). The Social Life of Camera-phones Images. Computer/Human Interaction 2007 Conference. San Diego, California (USA). (www.chi2007.org) (28-022011). https://citeseerx.ist.psu.edu/viewdoc/download?doi=10.1.1.137.4299\&rep=rep1\&t ype $=$ pdf

Vuopala, E., Guzmán, D., Aljabaly, M., Hietavirta, D., Malacara, L., \& Pan, C. (2020). Implementing a maker culture in elementary school - students' perspectives. Technology, Pedagogy and Education, 29(5), 649-664. 10.1080/1475939X.2020.1796776

Cómo citar: Blanco, M. (2022). La fotografía entre estudiantes de Periodismo y Comunicación Audiovisual de las universidades públicas andaluzas: consumo, cultura visual y una propuesta pedagógica. Revista KEPES, 19(25), 47-77. https://doi.org/10.17151/kepes.2022.19.25.3 